\title{
Five Hundred Patients with Memory Loss in One Clinic in India: Does the Prevalence Vary Between Communities?
}

\author{
Vijay Chandra ${ }^{\mathrm{a}, \mathrm{b}, *}$ and Veer Singh Mehta ${ }^{\mathrm{a}, \mathrm{b}}$ \\ a Primus Hospital, New Delhi, India \\ ${ }^{\mathrm{b}}$ Paras Hospitals, Gurgaon, Haryana, India
}

\begin{abstract}
This observational study reports on the cause of memory loss in 500 consecutive patients. It confirms the previously reported finding in a smaller sample of 100 patients. There have been several publications suggesting that the prevalence of dementia is lower in certain communities but the reason is not known. This study was conducted to see if it could explain the variation between communities. Also, the observation that dementia with Lewy bodies (24.4\%) outnumbers cases of Alzheimer's disease (5.8\%) has not been reported by any other investigators and needs to be verified. This finding could open a new topic of research and also help in the management of patients.
\end{abstract}

Keywords: 500 patients, dementia, dementia with Lewy bodies, India, memory loss

\section{INTRODUCTION}

Our previous research $[1,2]$ has described the variation in prevalence between India and the United States (US). Other researchers have found a variation between ethnic groups within the US [3]. Differences in the prevalence of dementia between communities has also been reported from Israel [4]. Studies have also mentioned the variations in mutations across countries in Asia. [5]. These publications from across the world leave little doubt that the prevalence of dementia varies across countries and communities. However, the effort to explain the differences have focused on genetic variations. Moreover, the relative proportion of types of dementia have not been reported and whether the variation in types of dementia can explain the difference in overall prevalence.

\footnotetext{
${ }^{*}$ Correspondence to: Dr. Vijay Chandra, Primus Hospital and Paras Hospitals, New Delhi and Gurgaon, Haryana, India. E-mail: vijaypcchandra@gmail.com.
}

Here we report the variation in causes of memory loss in a large clinical series from India.

\section{METHODS}

This article is an update of our previous report [6] in which we described the distribution of the types of dementia in our first 100 patients. We now present our findings on a much larger series of 500 patients seen in the same clinics. This is the largest series of patients from one clinic in India. We report the distribution of the types of memory loss and the educational level of patients and hypothesize why dementia with Lewy bodies (DLB) is not reported by clinicians elsewhere.

The Hospital Ethics Committee of Paras Hospitals has approved the design, data compilation, and publication of the results. No experiments involving human subjects or animals were done.

This is an observational study in which patients were identified from Paras Hospital, Gurgaon, Primus Hospital, Chanakyapuri, New Delhi and also from 
the private practice of one of the authors (VC). Patients were identified between 2015 and 2018. All the patients presented with the complaint of loss of memory or forgetting. 500 consecutive patients were included with no exclusion criteria. The patients were mostly residents of the National Capital Region of Delhi, which includes the city of New Delhi and the surrounding suburbs. Some patients came to the clinic after they did an internet search of Dementia clinics as well as of the qualifications and experience of doctors.

Each patient and their relatives underwent a detailed clinical interview by one of the investigators (VC), blood tests (including complete blood count, lipid profile, thyroid function tests, vitamin $\mathrm{B}, \mathrm{D}$, and folate level) and an MRI scan of the brain. MRI scans were interpreted in consultation with neuroradiologists, at either Paras Hospital or Primus Hospital. No genetic tests were performed. Formal neuropsychological tests were not conducted as they are time consuming, patients are multi-lingual, and most family members were not inclined to subject their relatives to these tests. The clinical interview was done ensuring a casual environment to make the patient at ease. The interview consisted of questions on current events specific to the gender of the patient, e.g., types of fruits and vegetables in season for women and latest political news for men. The next-of-kin were asked to provide specific examples of what the patient forgets and under what circumstances.

All patients were diagnosed with a specific cause of loss of memory. Dementia was diagnosed on the basis of a significant impairment in both cognitive function as well as in routine everyday activities [7]. The various types of dementia were diagnosed on the basis of established, and accepted, medical criteria: Alzheimer's disease (AD) [8], DLB [9], frontotemporal lobar degeneration (FTLD) [10], vascular dementia $(\mathrm{VaD})[11]$, mild cognitive impairment (MCI) [12], depression [13], and subjective cognitive decline (SCD) [14]. No specific checklist (except for DLB) was used for each type of dementia, rather the diagnosis was based on the clinical judgment of the principle investigator (VC).

\section{RESULTS}

The distribution of cause of memory loss in 500 consecutive patients seen at the Dementia clinic is shown in Table 1. Other than studying the relative proportion of cause of memory loss, no formal statistical tests were performed.

Only $5.8 \%$ of the patients were diagnosed as having AD. All these cases were in the age category 60 years and over, and the gender distribution among them was approximately equal. This percentage is lower than we reported in our first publication on the first 100 cases.

DLB (24.4\%) constituted the largest number of cases as in our previous series. These patients were over 60 years of age and their gender distribution was approximately equal.

There were only $2.8 \%$ of cases with FTLD, with approximately equal gender distribution, but the numbers are too small for a meaningful interpretation.

There were $8.6 \%$ cases of $\mathrm{VaD}$, and the majority of them were males in the age group 60 and over.

MCI was the second most common cause for seeking medical attention. This impairment was more common in those over 70 years of age, though there were some who were younger. The gender distribution between these patients was more or less equal.

Depression was the third most common cause of "memory loss", and was found in those who were

Table 1

Distribution of cause of memory loss in 500 patients seen in one clinic in India

\begin{tabular}{|c|c|c|c|c|c|c|c|c|c|c|c|c|c|c|c|c|}
\hline \multirow[t]{2}{*}{ Age } & \multicolumn{2}{|c|}{$\mathrm{AD}$} & \multicolumn{2}{|c|}{ DLB } & \multicolumn{2}{|c|}{ FTLD } & \multicolumn{2}{|c|}{$\mathrm{VaD}$} & \multicolumn{2}{|c|}{ MCI } & \multicolumn{2}{|c|}{ Depression } & \multicolumn{2}{|c|}{ SCD } & \multicolumn{2}{|c|}{ Misc } \\
\hline & $\mathrm{M}$ & $\mathrm{F}$ & $\mathrm{M}$ & $\mathrm{F}$ & $\mathrm{M}$ & $\mathrm{F}$ & M & $\mathrm{F}$ & $\mathrm{M}$ & $\mathrm{F}$ & $\mathrm{M}$ & $\mathrm{F}$ & $\mathrm{M}$ & $\mathrm{F}$ & $\mathrm{M}$ & $\mathrm{F}$ \\
\hline$<50$ & 1 & 2 & 0 & 0 & 1 & 0 & 2 & 0 & 0 & 2 & 10 & 6 & 2 & 2 & 3 & 0 \\
\hline $51-60$ & 2 & 0 & 2 & 1 & 1 & 3 & 2 & 1 & 3 & 4 & 9 & 7 & 1 & 4 & 8 & 5 \\
\hline $61-70$ & 3 & 4 & 11 & 10 & 4 & 1 & 7 & 2 & 18 & 8 & 15 & 10 & 8 & 3 & 9 & 6 \\
\hline $71-80$ & 6 & 6 & 29 & 18 & 2 & 0 & 12 & 9 & 20 & 23 & 12 & 8 & 9 & 4 & 20 & 5 \\
\hline$>81$ & 5 & 0 & 27 & 24 & 0 & 2 & 6 & 2 & 12 & 13 & 2 & 2 & 1 & 2 & 9 & 7 \\
\hline Total by gender & 17 & 12 & 69 & 53 & 8 & 6 & 29 & 14 & 53 & 50 & 48 & 33 & 21 & 15 & 49 & 23 \\
\hline Total (\%) by disease & \multicolumn{2}{|c|}{$29(5.8)$} & \multicolumn{2}{|c|}{$122(24.4)$} & \multicolumn{2}{|c|}{$14(2.8)$} & \multicolumn{2}{|c|}{$43(8.6)$} & \multicolumn{2}{|c|}{$103(20.6)$} & \multicolumn{2}{|c|}{$81(16.2)$} & \multicolumn{2}{|c|}{$36(7.2)$} & \multicolumn{2}{|c|}{$72(14.4)$} \\
\hline
\end{tabular}

$\mathrm{AD}$, Alzheimer's disease; DLB, dementia with Lewy bodies; FTLD, frontotemporal lobar degeneration; VaD, vascular dementia; MCI, mild cognitive impairment; SCD, subjective cognitive decline. 
younger than 60 years. Contrary to general belief, there were more males than females with depression.

SCD was diagnosed in $7.2 \%$ of subjects who selfreported "memory" decline, with no objective decline in cognition on formal testing. This category was not reported in our previous publication [6].

The miscellaneous conditions included a diverse range of diagnoses including phobia of dementia, dementia secondary to a medical illness, dementia due to normal pressure hydrocephalus, dementia with Parkinson's disease. and post-traumatic dementia.

\section{DISCUSSION}

\section{Educational level}

We had not recorded the education level in the first 100 patients. Previously many researchers had reported that lower education was a risk factors for dementia $[15,16]$, but later studies have refuted this finding [17] proposing that there may be a more consistent relationship when years of education reflected cognitive capacity.

We decided to enquire about the educational level of the patient from the next of kin. The findings are revealing.

\section{Rural patients}

In many of the villages in the late nineteenth century, there were no schools. Where there were schools, families were too poor to send their children to school. Families with land holdings considered it more important for boys to work in the field rather than go to school. Thus, educational level was not available in most rural patients.

\section{Urban patients}

Educational level was available in most urban patients, but some families thought it was an irrelevant question perhaps with "extraneous" considerations and did not wish to give this information. Many very elderly patients were brought by their grandchildren who were not aware of the educational level of their grandparents.

Thus, educational level was available on a relatively small group of patients. The sample on which information was available was considered as biased and unrepresentative and thus not appropriate for analysis.

\section{Why don't clinicians report dementia with Lewy} bodies?

The cardinal features of DLB as described in the review article of the DLB consortium [9] are:

- Dementia as a progressive cognitive decline which interferes with occupational functioning or activities of daily living;

- Fluctuating cognition;

- Recurrent visual hallucinations;

- REM sleep disorders;

- Features of parkinsonism.

In patients of DLB seen in our clinic, the dementia is usually mild permitting the patient to continue with some routine activities. Fluctuation is often prominent leading to family members believing that the patient is "pretending to be ill" and can be normal when he/she desires. Hallucinations, specifically visual hallucinations, are rarely reported by family members as there is no appropriate word in the local language for hallucinations. Frequently relatives report "dreams while awake" or talking to their long dead relatives. Some relatives report that the patient believes his/her spouse of 50 years is a thief. A few report that the patient imagines there are snakes or ants on the wall. These patients may be taken to psychiatrists who prescribe potent anti-psychotics in increasing doses until side-effects appear. REM sleep disturbance are hard for relatives to report. Finally, features of parkinsonism are diagnosed as Parkinson's disease, which is easier to diagnose and treat with syndopa.

Few busy clinicians will try to put all signs and symptoms into one diagnosis of DLB. There is now increasing awareness of "dementia" among General Physicians but rarely is there effort to try to determine the cause or type of dementia. Thus, the diagnosis of DLB is usually not established.

\section{Summary of discussion from the previous publication}

Most of the discussion of the results are as in our previous publication [6], and only the salient features will be repeated here.

As reported in our finding of 100 patients, while $\mathrm{AD}$ is reported to be the most common cause of degenerative dementia globally [18], in this series, DLB exceeds AD. Globally DLB is the second most common variety of degenerative dementia after $\mathrm{AD}[9]$. 
In this series, $\mathrm{VaD}$ due to large vessel or small vessel disease is not as common as expected, given the increasing incidence of stroke in India. The four common risk factors for cerebrovascular disease (diabetes, hypertension, tobacco use, and dyslipidemia) are rampant and increasing in South-East Asia [19]. Yet not many cases of cardiovascular disease report to hospitals; perhaps mortality is high outside the hospital.

Depression is a common cause of memory loss in this series. This may be due to older people living alone and away from their children who are often abroad. This has had a severe impact on the traditional caring system where the joint family featured prominently. It is also reported to be an under-diagnosed condition with patients presenting with other psychosomatic symptoms such as "forgetting". It is also an under-treated condition with most patients (as in this series) refusing treatment or being referred to a psychiatrist.

MCI causes cognitive changes that are serious enough to be noticed by the individuals experiencing them and or by their family members. Yet these changes are not severe enough to interfere with routine life or independent functioning.

SCD is receiving increasing attention as a risk factor for future AD [14]. The categorization of SCD is largely based on self-reported symptoms by the individual and the interpretation by the clinician. Since there are no specific neuropsychological tests or scores for its diagnosis, the conclusion is often subjective on the part of the clinician.

It should be noted that the differential diagnosis of the types of dementia done here was clinical. They were not based on laboratory and nuclear medicine tests as these are unaffordable to most in a less resourced country where medical expenses are paid out of pocket. Consequently, no sophisticated tests, such as amyloid imaging (not available in India as yet) or fMRI were done.

This study is the first, largest, and only case series examining the distribution of cause of memory loss seen in a Dementia clinic.

Other studies [20] generally deal with populationbased studies of the prevalence of all dementias, with small number of subjects. They are conducted for awareness generation and planning. The objective of this study (to study the subtypes of memory loss) is different from the population-based studies of the prevalence of dementia. Moreover, there are no clinical series of patients describing the relative proportion of types of dementia.
There is limited information on risk factors for dementias in the cases studied. Cost is a major consideration among families of patients, many of whom have given up their jobs or are paying substantial sums of money for caregivers. Therefore, our established way of practice in the Dementia clinic is to recommend those tests which help us make a diagnosis (MRI brain). Other tests such as blood sugar and vitamin levels are available in most patients but not for the entire sample, thus meaningful analysis is not possible.

As mentioned before, the best-known risk/protective factor, educational level, cannot be assessed in a structured manner, particularly in older patients who have been farmers or housewives. Thus, asking a patient the number of grades of education would not apply. Tests of research interest (APOE4) were not recommended.

The distribution of dementia types in this much larger series than the first report is surprising. Why DLB cases should outnumber cases of AD remains unknown. One possible explanation could be the variation in genetic makeup of the Indian population which are widely known. For example, $\mathrm{N}$-acetyltransferase 2 gene polymorphism as a predisposing factor for phenytoin toxicity in the Indian population [21], HLA-B 1502 allele and its role in carbamazepine toxicity in Indians and other Asian communities [22], and more recently the association of HLA with oxcarbazepine-induced toxicity in Asians [23] are well documented. The role of APOE4 in $\mathrm{AD}$ is also established and its distribution is similar between the Indian and US populations. However, the prevalence of dementia is lower in India compared to the US [24]. Not much is known yet about the genetic abnormalities in DLB. Perhaps when the genetic markers in DLB are identified and extensively available in genetic laboratories, this could shed light on this difference.

\section{Conclusion}

This is the only study to report on the relative frequency of cause of memory loss in a clinical series. The observation that DLB outnumbers AD should be verified by other researchers. Perhaps genetic researchers would like to investigate the genetic makeup of patients clinically diagnosed with DLB. Clinicians should be aware that "dementia" is not the "end" of the diagnostic workup and determining the cause of dementia is important. As clinicians have a saying, "The ABC of Parkinson's disease, it's not just 
about shaking" [25], it can also be said that "Everyone who forgets, does not have Alzheimer's disease."

\section{CONFLICT OF INTEREST}

The authors have no conflict of interest to report.

\section{FUNDING}

There was no funding for this study.

\section{REFERENCES}

[1] Chandra V, Ganguli M, Pandav R, Johnston J, Belle S, DeKosky ST (1998) Prevalence of Alzheimer's disease and other dementias in rural India - The Indo-US study. Neurology 51, 1000-1008.

[2] Chandra V, Pandav R, Dodge HH, Johnston JM, Belle SH, DeKosky ST, Ganguli M (2001) Incidence of Alzheimer's disease in rural population in India - The Indo-US study. Neurology 57, 985-989.

[3] Mayeda ER, Glymour MM, Quesenberry CP, Whitmer RA (2016) Inequalities in dementia incidence between six racial and ethnic groups over 14 years. Alzheimers Dement 12, 216-224.

[4] Keret O, Shochat T Steiner I Glik A (2018) Non-Ashkenazi Jewish origin is associated with early onset Alzheimer's disease. J Alzheimers Dis 65, 877-884.

[5] Bagyinszky E, Youn YC, AN SS, Kim S (2016) Mutations, associated with early-onset Alzheimer's disease, discovered in Asian countries. Clin Interv Aging 11, 1467-1488.

[6] Chandra V, Mehta VS (2017) Distribution of types of dementia in the first 100 patients seen in a dementia clinic in India. J Alzheimers Dis 59, 797-801.

[7] Bouchard RW (2007) Diagnostic criteria for dementia. Can J Neurol Sci 34 Suppl 1, S11-18.

[8] McKhann GM, Knoopmam DS, Chertkow H, Hyman BT, Jack CR, Kawas CH, Klunk WE, Koroshetz WJ, Manly JJ, Mayeux R, Mohs RC, Morris JC, Rossor MN, Scheltens P, Carrillo MC, Thies B, Weintraub S, Phelps $\mathrm{CH}$ (2011) The diagnosis of dementia due to Alzheimer's disease: Recommendations from the National Institute on Aging-Alzheimer's Association workgroups on diagnostic guidelines for Alzheimer's disease. Alzheimers Dement 7, 263-269.

[9] McKeith IG, Dickson DW, Lowe J, Emre M, O'Brien JT, Feldman H, Cummings J, Duda JE, Lippa C, Perry EK, Aarsland D, Arai H, Ballard CG, Boeve B, Burn DJ, Costa D, Del Ser T, Dubois B, Galasko D, Gauthier S,. Goetz CJ, Gomez-Tortosa E, Halliday G, Hansen LA, Hardy J, Iwatsubo T, Kalaria RN, Kaufer D, Kenny RA, Korczyn A, Kosaka K, Lee VMY, Lees A, Litvan I, Londos E, Lopez OL, Minoshima S, Mizuno Y, Molina JA, Mukaetova-Ladinska EB, Pasquier F, Perry RH, Schulz JB, Trojanowski JQ, Yamada M (2005) Diagnosis and management of dementia with Lewy bodies: Third report of the DLB consortium. Neurology 65, 1863-1872.

[10] Coyle-Gilchrist ITS, Dick KM, Patterson K, Rodriquez PV, Wehmann E, Wilcox A, Lansdall CJ, Dawson KE, Wiggins J, Mead S, Brayne C, Rowe JB1 (2016) Prevalence, characteristics, and survival of frontotemporal lobar degeneration syndromes. Neurology 86, 1736-1743.
[11] Jellinger KA (2008) The pathology of "vascular dementia": a critical update. J Alzheimers Dis 14, 107-123.

[12] Marilyn SA, DeKosky ST, Dickson D, Dubois B, Feldman HH, Fox NC, Gamst A, Holtzman DM, Jaqust WJ, Petersen RC, Snyder PJ, Carrillo MC, Thies B, Phelps CH (2011) The diagnosis of mild cognitive impairment due to Alzheimer's disease: Recommendations from the National Institute on Aging-Alzheimer's Association workgroups on diagnostic guidelines for Alzheimer's disease. Alzheimers Dement 7, 270-279.

[13] American Psychiatric Association (2013) Diagnostic and Statistical Manual 5. American Psychiatric Association, Washington, DC.

[14] Molinuevo JL, Rabin LA, Amariglio R, Buckley R, Dubois B, Ellis KA, Ewers M, Hampel H, Kloppel,S, Rami L, Reisberg B, Saykin S, Smart CM, Snitz BE, Sperling R, van der Flier WM, Wagner M, Jessen F; Subjective Cognitive Decline Initiative (SCD-1) Working Group (2017) Implementation of subjective cognitive decline criteria in research studies. Alzheimers Dement 13, 296-311.

[15] Katzman R (1993) Education and the prevalence of dementia and Alzheimer's disease. Neurology 43, 13-20.

[16] Mortimer JA, Graves AB (1993) Education and other socioeconomic determinants of dementia and Alzheimer's disease. Neurology 43, S39-S44.

[17] Sharp ES, Gatz M (2011) The relationship between education and dementia: an updated systematic review. Alzheimer Dis Assoc Disord 25, 289-304.

[18] Ferri CP, Prince M, Brayne C, Brodaty H, Fratiglioni L, Ganguli M, Hall K, Hasegawa K, Hendrie H, Huang Y, Jorm A, Mathers C, Menezes PR, Rimmer E, Scazufca M, Alzheimer's Disease International (2005) Global prevalence of dementia: a Delphi consensus study. Lancet 366, 2112-2117.

[19] Gupta R, Joshi P, Mohan V, Reddy KS, Yusuf S (2008) Epidemiology and causation of coronary heart disease and stroke in India. Heart 94,16-20.

[20] Das SK, Pal S, Ghosal MK (2012) Dementia: Indian scenario. Neurol India 60, 618-624.

[21] Adithan, C, Subartha, A (2016) NAT2 gene polymorphism: covert drug interaction causing phenytoin toxicity. Indian $J$ Med Res 143, 542-544.

[22] Mehta TY, Prajapati LM, Mittal B, Joshi CG, Sheth JJ, Patel DB, Dave DM, Goyal RK (2009) Association of HLA-B 1502 allele and carbamazepine-induced Stevens-Johnson syndrome among Indians. Indian J Dermatol Venereol Leprol 75, 579-582.

[23] Chen CB, Hsiao YH, Wu T, Hsih MS, Tassaneeyakul W, Jorns TP, Sukasem C, Hsu CN, Su SC, Chang WC, Hui RC, Chu CY, Chen YJ, Wu CY, Hsu CK, Chiu TM, Sun PL, Lee HE, Yang CY, Kao PH, Yang CH, Ho HC, Lin JY, Chang YC, Chen MJ, Lu CW, Ng CY, Kuo KL, Lin CY, Yang CS, Chen DP, Chang PY, Wu TL, Lin YJ, Weng YC, Kuo TT, Hung SI, Chung WH; Taiwan Severe Cutaneous Adverse Reaction Consortium (2017) Risk and association of HLA with oxcarbazepine-induced cutaneous adverse reactions in Asians. Neurology 88, 78-86.

[24] Ganguli M, Chandra V, Kamboh MI, Johnston JM, Dodge HH, Thelma BK, Juyal RC, Pandav R, Belle SH, DeKosky ST (2000) Apolipoprotein E polymorphism and Alzheimer's disease: The Indo-US Cross-National Dementia Study. Arch Neurol 57, 824-830.

[25] Woodbridge S (2019) The ABCs of Parkinson's: It not just about shaking. Parkinson's News Today, January 9, https:// parkinsonsnewstoday.com/2019/01/09/abcs-parkinsonsnot-just-about-shaking-n/ 